\title{
OER Usage by Instructional Designers and Training Managers in Corporations
}

\author{
Eli Merkel and Anat Cohen \\ Tel Aviv University, Tel Aviv, Israel \\ elimerkel@mail.tau.ac.il; anatco@post.tau.ac.il
}

\begin{abstract}
Since the development of Open Educational Resources (OERs), different models regarding the usage of these resources in education have appeared in the literature. Wiley's 4-Rs model is considered to be one of the leading models. Research based on Wiley's model shows that using materials without making changes is the most common use. Compared to the extensive literature regarding OER usage in education, the literature barely deals with OER usage by instructional designers or training managers in corporations. The purpose of this research is to examine the OER usage of these two stakeholders, distinguishing between Little and Big OER repositories, in which Little OER repositories such as YouTube and Wikipedia aren't necessarily designed to fulfill educational purposes. Findings show that these stakeholders almost use only Little repositories and that their usage level is higher than what is documented in the literature: they mostly Revise-modify the form of the resource, and Remix-combine different resources to create new ones. These differences can be explained by the fact that materials from Little OER repositories are raw materials, requiring further editing and adjustment. Significant differences between instructional designers' and training managers' usage of OERs were found regarding the Reuse level of resources from internal repositories and the Google Images repository, and the frequency of this Reuse.
\end{abstract}

Keywords: OER, Open Educational Resources, instructional designers, training managers, corporate

\section{Introduction}

The term, Open Educational Resource (OER), was first coined in 2002 by the UNESCO committee (World Forum of UNESCO Chairs, 2002)) and was defined by Hylén (2006, p. 1) as "Digitized materials offered freely and openly for educators, students, and self-learners to use and re-

Material published as part of this publication, either on-line or in print, is copyrighted by the Informing Science Institute. Permission to make digital or paper copy of part or all of these works for personal or classroom use is granted without fee provided that the copies are not made or distributed for profit or commercial advantage AND that copies 1) bear this notice in full and 2) give the full citation on the first page. It is permissible to abstract these works so long as credit is given. To copy in all other cases or to republish or to post on a server or to redistribute to lists requires specific permission and payment of a fee. Contact Publisher@InformingScience.org to request redistribution permission. use for teaching, learning, and research". Following Hylén's definition, it can be assumed that instructional designers in the training world might have interest in these resources since they already use new technologies and incorporate learning objects into their designs (Duncan, 2009).

OERs can usually be found in varied repositories. The literature suggests a

Editor: Janice Whatley

Submitted May 25, 2015; Revised September 6, 2015; Accepted: October 4, 2015 An earlier, shorter version of this paper was presented at the Chais conference 2015, in Raanana, Israel, and included in Y. Eshet-Alkalai, I. Blau, A. Caspi, N. Geri, Y. Kalman, \& V. Silber-Varod (Eds.), Proceedings of the 10th Chais Conference for the Study of Innovation and Learning Technologies 2015: Learning in the Technological Era. Raanana: The Open University of Israel. 
distinction between these repositories based on different theoretical frameworks, e.g., distribution and sharing models (Shmueli, Reisman, \& Sperling, 2010): Big repositories and Little repositories (Weller, 2010). A Big OER repository is defined as an institutional repository for teaching and learning objectives and is usually of high quality. It is presented in a unified style and forms part of a time-limited, focused project, has a portal, and is associated with research and data. A Little OER repository is defined as an individually produced, low cost resource that can be produced by anybody, not just educators, and may not have explicit educational objectives. It is usually perceived to have low production quality and is shared through a range of third party sites and services. Reference to Little OER repositories, such as Wikipedia, posts and blogs on Wordpress, Slideshare, Wikispaces, and images on Flicker, which do not contain the classic learning objects, can be found in the literature (Hylén, 2006; Keegan \& Bell, 2011; Rolfe, Williams, \& Windle, 2012; Weller, 2010).

Types of OER usage are varied. In his 4-Rs model, Wiley (Hilton, Wiley, Stein, \& Johnson, 2010) differentiates four levels of reuse: using the content without changes (Reuse); sharing copies of the content with others (Redistribute); adapting, modifying, translating, or changing the form of the content (Revise); and combining different OERs to create a new source (Remix). The literature suggests that the last two levels represent a minor part of the possible utilization of OERs (Hilton, Wiley, \& Lutz, 2012; Rolfe et al., 2012). Through the reuse of OERs, teaching and learning processes can be enhanced (Friesen, 2009; Hylén, 2006).

OER repositories might be relevant for corporate instructional designers who are required to supply training solutions of considerable content and domains. There is no doubt that organizations have different training needs, thus the requirement for particular content; however, instructional design in organizations often revolves around a standard set of topics. Varied resources are available for instructional designers, such as internal manpower, internal organizational repositories, external repositories, and repositories which are not necessarily meant for learning purposes. These last two might be open Big or Little repositories and, thus, are accessible to instructional designers and training managers. In addition, it seems that there are different work characteristics for instructional designers working in corporate organizations in comparison to instructional designers in the academic and educational domains. Therefore, this research aims to examine which OER repositories are used by the instructional designers working in corporate organizations and whether their usage characteristics are different from those described in the literature. This research broadens the little knowledge that exists regarding the use of OERs by instructional designers and training managers in corporations, especially in Israel, and provides insight into the way they are used.

\section{Background}

The impact of open learning resources in higher education was discussed during UNSCO's education forum in 2002. Out of that forum came the term OERs (Johnstone, 2005). Around this principal, a movement was developed, and at its heart lies the simple and powerful idea that the world's knowledge is a public good and that technology in general and the World Wide Web in particular, provide an extraordinary opportunity for everyone to share, use, and reuse that knowledge (Smith \& Casserly, 2006). Since the time the term originated, there have been several attempts to clarify the definition of OERs. Hylén (2006) defines OER as digital materials offered freely and openly to reuse for education and research. Hylén also adds that OERs contain educational content, software tools, and application resources. A more detailed definition of OERs was suggested by the William and Flora Hewlett foundation, which is considered part of the OER movement leadership: "Teaching, learning, and research resources that reside in the public domain or have been released under an intellectual property license that permits their free use or repurposing by others. OERs include full courses, course materials, modules, textbooks, streaming 
videos, tests, software, and any other tools, materials, or techniques used to support access to knowledge" (D'Antoni, 2009, p. 3).

The meaningful advantage of these resources being free for use turns out to have profound implications; for example, in an updated study of eight US colleges that had adopted the use of OERs, Hilton, Robinson, Wiley, and Ackerman (2014) found a significant cost reduction for their students worth thousands of dollars. Beyond that, the money savings did not come at the expense of the quality of materials nor the students' academic achievements. A study from 2013 compared the academic achievements of students who used OERs to the achievements of students who used learning books, and found no difference (Hilton, Gaudet, Clark, Robinson, \& Wiley, 2013).

Generally, OERs can be found in various dedicated repositories. The literature suggests several theoretical frameworks to distinguish between these repositories. Shmueli et al. (2010) categorize types of online learning material repositories based on distribution and sharing models; Cohen, Kalimi, and Nachmias's (2013) distinction is of local and global repositories. Hylén (2006) provides a different angle to the characterization of repositories by placing them on two axes: scale of operation (small/large), and provider of materials (institution/community). Although the terminology is similar, Weller (2010) presents a slightly different approach to the classification of repositories. He groups the repositories in terms of Big repositories and Little repositories. A Big OER repository is usually defined as an institutional repository for teaching and learning objectives and is usually of high quality. It is presented in a unified style and forms part of a timelimited, focused project, has a portal, and is associated with research and data. A Little OER repository is defined as an individually produced, low cost resource that can be produced by anybody, not just educators, and may not have explicit educational objectives. It is usually perceived to have low production quality and is shared through a range of third party sites and. Indeed, the literature refers to Little OER repositories as not containing the classic learning objects such as Wikipedia, posts and blogs on Wordpress, Slideshare, Wikispaces, and images on Flicker (Hylén, 2006; Keegan \& Bell, 2011; Rolfe et al, 2012; Weller, 2010). Despite this categorization, one should notice that Weller's terminology might be misleading. The repository size in terms of number of objects and number of users reflects the opposite picture. In their research, Zervas, Alifragkis, and Sampson (2014) analyzed the functionality of 49 Big OER repositories and presented data regarding the number of objects and users for each repository. They found that the biggest repositories contain no more than several hundreds of thousands of objects, and they located only two repositories with more than one hundred thousand users (e.g., Curriki and Merlot). This contrasts Little repositories such as Wikipedia, which contains more than 26 million articles in more than 250 languages and serves more than 500 million readers each month (Mesgari, Okoli, Mehdi, Nielsen, \& Lanamäki, 2015).

Detailed examination of OER repositories, whether they are Big or Little, reveals a variety of objects that are used as OERs. In their 2009 review, Wiley and Gurrell display the development of several OER projects such as Internet Archive, Wikipedia, Connexions, and MIT OpenCourseWare; each contains a wide variety of objects. Wikipedia includes encyclopedic items that are mainly text based; Internet Archive is an online library containing websites, moving images, texts, audio, and recently added educational resources (Murphy, Hashim, \& O'Connor, 2007); Connexions is an Internet repository containing educational content focusing on books, organized in modules that include tools for editing and reorganizing content (Burrus, 2014); MIT OpenCourseWare is a repository containing the academic content of entire courses from all the MIT university faculties, where some of the courses even include full video lectures (d'Oliveira, Carson, James, \& Lazarus, 2010). Thus, it seems that the types of OERs are varied - from small learning objects to full courses.

A significant aspect of the definition of OERs is the extent of openness, which is the way they can be used. Obviously, OERs are used as a knowledge source for the learner, but a more ad- 
vanced OER use is the Reuse: usage which exceeds a simple reading or reviewing of the learning object. Hylén (2006) states that Reuse of OERs means that the end-user should be able not only to use or read the resource but also to adapt it and build a new OER upon it. By the Reuse of OERs, teaching and learning processes can be made efficient, and their quality can be improved via adaptation to local needs, improvement, renovation, adding or removing layers, and combining several resources (Friesen, 2009; Hylén, 2006). However, there is always the concern that information overload might cause confusion, create a mismatch, or waste time during the data search due to a lack of consistent classification schemes. There is additional concern for the quality of the data because of the absence of appropriate evaluation tools (Nash, 2005).

Hilton et al. (2010) expanded the definition of the Reuse types. In their research, they present Wiley's 4-Rs model, in which four levels of Reuse are differentiated. The model defines the possible openness levels of OERs, but in a broader sense the model can be used to define the usage types of OERs:

1. Reuse - the most basic usage type, using the content unaltered and verbatim.

2. Redistribute - sharing copies of the content with others.

3. Revise - adapting, modifying, translating, or changing the form of the content.

4. Remix - the highest level of reuse, combining different OERs to create a new source.

The literature suggests that the last two levels represent a minor part of the utilization of OERs. Hilton, Wiley, and Lutz (2012) examined OER repositories of digital books in order to map the usage types of the repository's users. They concluded that Reuse is the most popular usage type, and that the Revise and Remix usage types, although they seem to be appealing for use, represent only $7.5 \%$ of overall usage. This finding is in line with what is known from the literature regarding the Reuse of OERs from other repositories. For example, the Rolfe et al. (2012) research, in which the usage types of medical OERs in a specific repository were examined, found that $99 \%$ of users didn't implement any changes to the content, but simply reused it. Hilton et al. (2012) found that the easier it is to make changes to an OER, the more changes people will make. Nevertheless it is important to mention that this research was conducted on a repository that enabled the option to track changes made on its objects. A major limitation of the research was the dark reuse of content - cases in which the users Revise or Remix objects outside of the system without the researchers knowing.

In the corporate world, a requirement for instructional design turns up when someone in the corporation, usually a manager, identifies a performance gap that requires a training treatment. According to the needs and the target audience, the instructional designer decides what the required solution is and develops manuals, scripts, video tutorial, computer based solutions, or tests (Gordon \& Zemke, 2000). A substantial part of learning solutions might combine technological elements; therefore, instructional designers might have interest in OERs since they already use new technologies in their projects and incorporate learning objects from the web in their designs (Duncan, 2009). Additionally, given the global economic condition, organizations are increasingly forced to reduce manpower while simultaneously being required to increase the productivity of their remaining employees. In such an environment the instructional designers' role becomes more significant, and they are required to increase the quality of instructional programs using ever more efficient methodologies (Roytek, 2010). Therefore, instructional designers might find OER repositories useful since they contain high quality learning objects likely to be relevant for them, answering the organization's demand for efficiency. There is no doubt that considerable differences can be found between organizations in regard to their training needs and vocational training, and thus in their different content needs. However, in the learning development world, in most organizations, there are a few common fundamental topics that can be found. Different and 
varied resources are available for instructional designers who develop training materials such as: internal manpower, internal organizational repositories, external repositories, and repositories which are not necessarily meant for learning purposes. The latter might be OER repositories Big or Little - thus accessible for instructional designers. In addition, it seems that different OER usage can be found when comparing instructional designers working in corporations to instructional designers in the academic and educational domains due to the dissimilar nature of their work. Actually, publication regarding OER usage in the corporate world is scarce, as it seems that the literature has mostly focused on the academic and educational domains. Even when the literature deals with OER issues in the corporate world, it is mostly from the point of view of how the corporation is using the repository knowledge, and not its training division. For example, OrriBadia (2015) describes a case in which the L'Oréal Company chose to train 160 employees to improve their presentation skills via a Massive Open Online Course (MOOC) and another example is an OER that was established for the food industry (Geith, Vignare, Bourquin, \& Thiagarajan, 2010). Therefore, this research aims to examine which OER repositories are used by the instructional designers working in corporations, and whether their usage characteristics are different from those outlined by the literature.

\section{The Study}

The current study explores the corporate training development domain, focusing on two main stakeholders - instructional designers (content developers of face-to-face and online training) and training managers - in order to examine the types of repositories they use and their usage levels. The claim was that different organizations have their own unique characteristics, thus their learning and training needs are unique. Therefore, it was hypothesized that only a few external institutional repositories (Big) are used for content development in corporations, mainly due to compatibility issues and irrelevancy of other corporate content. Furthermore, it was theorized that instructional designers who use external repositories are required to make adjustments to learning objects obtained from these repositories, hence deriving the following research hypotheses:

- Instructional designers and training managers use the Little OERs.

- Since Little repositories do not contain structured learning items, instructional designers and training managers mainly utilize the Revise and Remix levels of use, which the literature indicates as less than $10 \%$ of common use.

Accordingly, the research questions are:

- Which OER repositories are used by the instructional designers of corporations? Do they use Little OERs?

- If instructional designers of corporates do use Little OERs, what is the level of use in accordance with Wiley's 4-Rs model?

- Are there any differences regarding the usage level of instructional designers and training managers?

\section{Methodology}

The research tool was a questionnaire, which was distributed to instructional designers and training managers in corporations through the following: Google Docs, by e-mail; relevant forums related to corporate training in LinkedIn; as well as Facebook groups of instructional designers and training managers. The full questionnaire in Hebrew can be found at the following link: http://tinyurl.com/qe4hkbz, while the translated questionnaire in English can be found in the Appendix. 
The questionnaire was designed according to the research questions, and the usage scale was based mainly on the 4-Rs model (Hilton et al., 2010). It was mostly focused on the usage levels of the items located in different kinds of repositories and their usage frequency, which was measured by a Likert scale.

The questionnaire was composed of four major parts:

- General data - demographic data of the participant such as age, gender, role, and nature of his/her job with an emphasis on learning material types developed by him/her.

- Internal repositories - participants were asked to report whether their place of work has an internal repository, and their usage type.

- External repositories - participants were asked to report which external repositories they use, and their usage type.

- Sharing - participants were asked to report whether they share the learning objects that they develop.

Regarding the external repositories, it should be noted that this part had two segments: in the first segment, participants were asked to name the Big repositories that they use and describe their usage level. In the second segment, participants received a list of popular Little repositories from diverse disciplines and were asked to report whether they use them, and if so, to also describe their usage level. In addition, participants had the option to list other Little repositories that they use and describe their usage type. The main reason for focusing on popular Little repositories was to obtain a sufficient amount of data for statistical analysis. The chosen repositories were:

- YouTube - a popular website used for sharing videos and movies, containing millions of videos and movies.

- TED - a popular website containing short videos of lectures and movies from varied domains and topics.

- Google Images - a search engine containing millions of pictures.

- Flicker - a website used for sharing pictures, containing millions of pictures.

- Wikipedia - an encyclopedia website, containing free content and millions of informative articles.

The questionnaire was sent to the targeted population of the study by e-mail and through posts in relevant Facebook and LinkedIn forums. The mails and posts included an explanation of the study aims and a request for participation. The questionnaire included further explanation and guidelines regarding how to fill it out and was voluntarily completed online by Israeli participants in the month of June, 2014.

According to the analysis of the completed questionnaires, the population of this study consisted of 50 participants from the field of training, from 29 corporate organizations across Israel of which there were 16 men and 34 women. $62 \%$ of the participants were instructional designers and $38 \%$ of them were training managers. The average age of the participants was 34.5 , and their average number of years of experience in the industry was 6.9. The participating organizations included companies from varied domains such as finance, food industry, and technology. 


\section{Findings}

\section{Characteristics of Learning Resources Developed in Corporations}

The study examined the types of learning resources which were developed by the participants, their topics, and the development frequency of each resource. A list of common and popular corporate training topics was shown to the participants. The participants were asked which topics they developed as learning content. The options were sales, service, technical topics, regulations, and other (the participants were able to report what kind of other contents they developed for learning purposes). The results show that the developed learning items deal with service, sales, technical topics, and regulations (Figure 1).

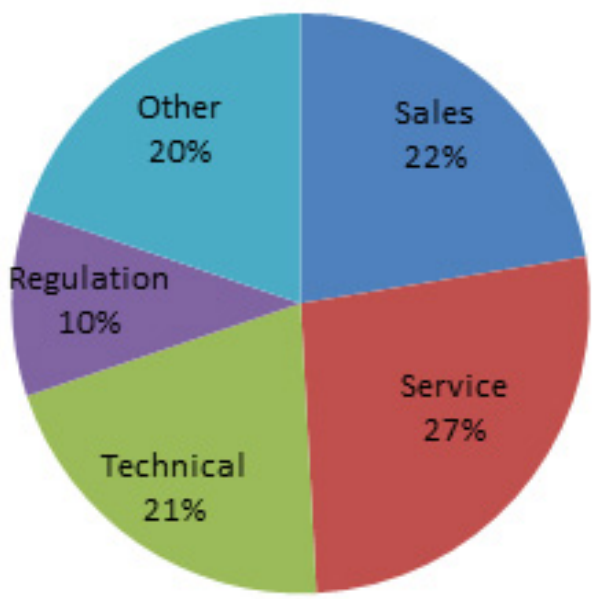

Figure 1. Segmentation of learning resource topics

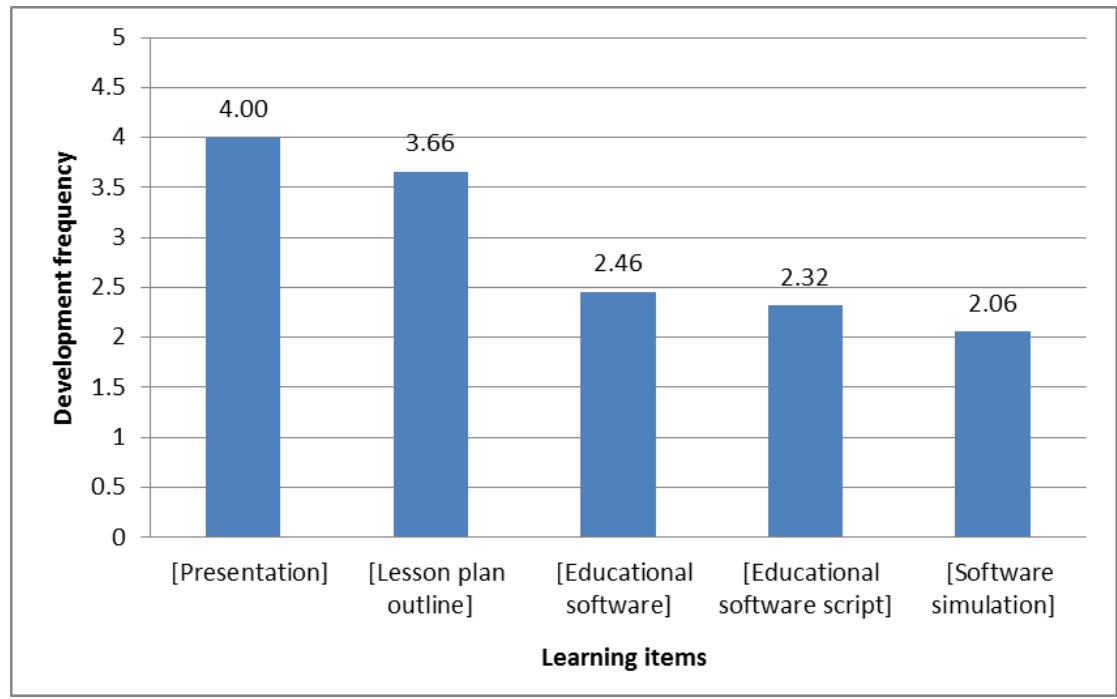

Figure 2. Types of learning objects and development frequency

Figure 1 presents the major topics of learning resources developed in corporate organizations. Service (27\%), Sales (22\%), and Technical (21\%) were found to be the major topics of learning resources developed in corporate organizations, with a balanced division. Regulation was only 
$10 \%$ of developed learning resources. The category of Other did not result in a clear trend toward a specific topic. In addition, participants were presented with common corporate learning items such as presentations and software simulation and were asked to report the development frequency of these items on a 1-5 Likert scale $(1=$ never; $2=$ rarely; $3=$ sometimes; $4=$ often; $5=$ mostly).

As shown in Figure 2, the learning item that had the highest development frequency was Presentation (4.00 on average), followed by Lesson plan (3.66 on average). Educational software (2.46 on average), Educational software script (2.32 on average), and Software simulation (2.06 on average) were far behind.

\section{The Usage of Internal Repositories}

Part of the questionnaire examined whether there were internal repositories in the participants' working environments and whether the participants use them. In addition, types and usage levels of participants' learning items were explored. The findings show that $92 \%$ of organizations have an internal repository and that $87 \%$ of the participants frequently use these internal repositories. In order to examine the types of learning items that are available in the internal repositories, and the search frequency of these items, the common corporate learning items were presented to the participants and they were asked to rate their search frequency on a 1-5 Likert scale $(1=$ never; 2 = rarely; $3=$ sometimes; $4=$ often; $5=$ mostly).

Figure 3 shows that in accordance with the development frequency of the different types of learning items, the most searched item was Presentation (3.59 on average), followed by Lesson plan outline (3.21 on average). Educational software (2.76 on average), Educational software script (1.81 on average), and Software simulation (1.69 on average) were, again, far behind.

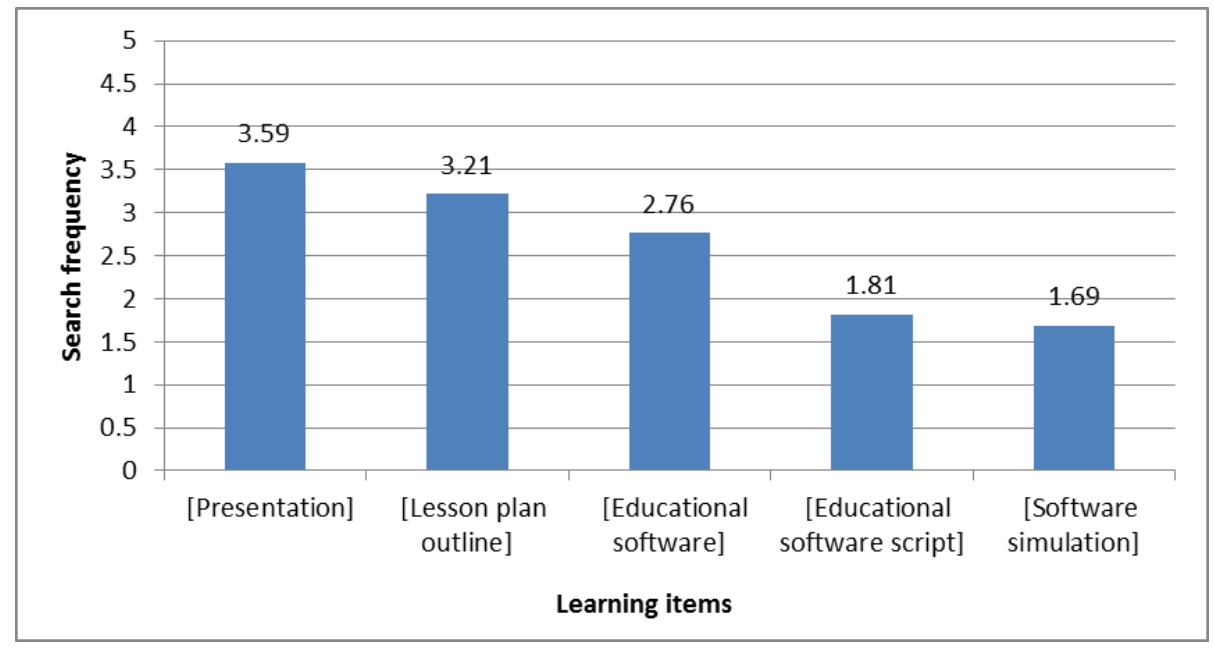

Figure 3. Types of learning items retrieved from internal repositories, and their search frequency

The participant usage level of learning items available in the internal repositories was examined, as well. Different levels of learning item usage were presented to the participants, and they were asked to rate their usage frequency for each level. The different levels were based on Wiley's 4Rs model; however, in this current study only three out of the four Reuse levels were examined. The fourth level of Reuse, Redistribute - distributing free learning materials - was not examined, since it does not have relevance to the role of instructional designers. Table 1 outlines the congruence between the model's definitions and the options that were given to the participants in the questionnaire. 
Table 1. The congruence between Wiley's 4-Rs model and the answer options on the questionnaire

\begin{tabular}{|c|l|l|l|}
\hline The 4 Rs & \multicolumn{1}{|c|}{ Reuse } & \multicolumn{1}{c|}{ Revise } & \multicolumn{1}{c|}{ Remix } \\
\hline Definition & $\begin{array}{l}\text { The most basic usage } \\
\text { level, using the content } \\
\text { unaltered and verbatim }\end{array}$ & $\begin{array}{l}\text { Adapting, modifying, } \\
\text { translating, or chang- } \\
\text { ing the form of the } \\
\text { content }\end{array}$ & $\begin{array}{l}\text { The highest level of } \\
\text { Reuse, combining } \\
\text { different OERs to } \\
\text { create a new source }\end{array}$ \\
\hline $\begin{array}{c}\text { Description in the } \\
\text { questionnaire }\end{array}$ & $\begin{array}{l}\text { Using the learning item } \\
\text { for informational pur- } \\
\text { poses only/using the } \\
\text { learning item in its } \\
\text { original form, just as it } \\
\text { appears in the reposito- } \\
\text { ry }\end{array}$ & $\begin{array}{l}\text { Creating changes and } \\
\text { adjustments in the } \\
\text { learning item accord- } \\
\text { ing to my needs }\end{array}$ & $\begin{array}{l}\text { Creating changes } \\
\text { and combining dif- } \\
\text { ferent learning items } \\
\text { according to my } \\
\text { needs }\end{array}$ \\
\hline
\end{tabular}

The participants were asked to report on the frequency of their Reuse for each level. The usage levels and the frequency of Reuse were rated on a 1-5 Likert scale $(1=$ never; $2=$ rarely; $3=$ sometimes; $4=$ often; $5=$ mostly), as well. The findings are presented in Figure 4 . As the Figure shows, the most popular usage levels are "creating changes and adjustments in the learning item according to my needs" (3.67 on average) and "creating changes and combining different learning items according to my needs" (3.64 on average). This means that Revise and Remix are the most frequent answers, respectively. They are followed by "using the learning item for information purposes only" ( 3.53 on average), and far behind with "using the learning item in its original form, just as it appears in the repository" (2.36 on average), which correspond to the first two levels of Reuse.

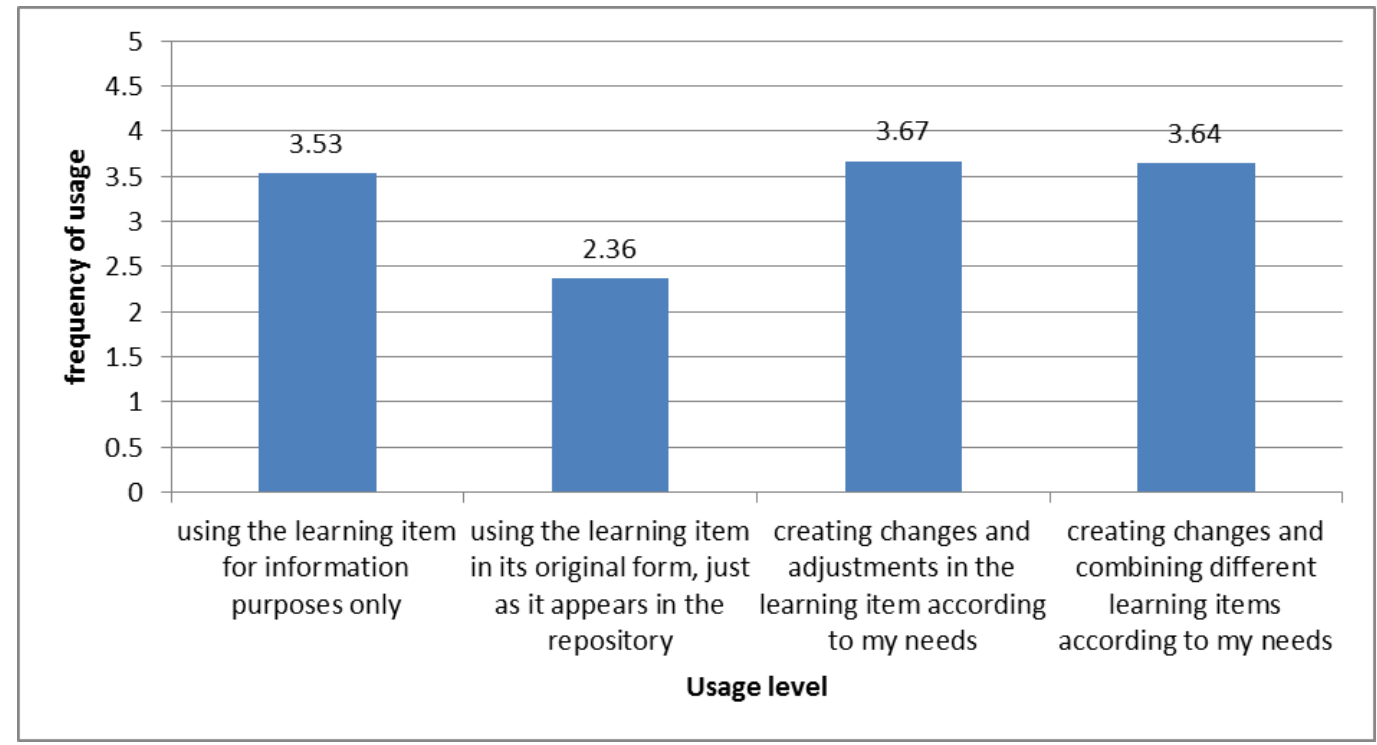

Figure 4. The frequency of usage level

\section{The Usage of External Big Repositories}

$49 \%$ of the participants answered positively to the question, "Do you use online repositories containing learning items when you are working on training development?" Subsequently, the participants were asked to report the repositories that they use and on what level. It is noted that alt- 
hough the questionnaire gave clear and specific guidance to the participants, asking them to only list repositories containing items which are clearly dedicated to learning such as presentations, lesson plan outlines, and educational software, and not to list learning items such as Google Images, forums, or newsletters, most of the participants still reported only Little repositories such as Wikipedia and YouTube. The small number of participants who did report using the relevant repositories (Big repositories) referred to pre-paid repositories, which did not fit the OER definition. Therefore, the results presented in this section could not be subjected to statistical analysis.

\section{The Usage of External Little Repositories}

The popular Little repositories - YouTube, Google Images, Wikipedia, Flicker, and TED - were presented to the participants, and they were asked whether they use these repositories and at what level. In addition, participants were able to report their usage of other Little repositories. As shown in Table 2, YouTube is the most popular repository among participants of the current study; 47 participants (96\%) referred to this repository and reported that they use it when they develop learning materials. Google Images was also found to be a popular repository for developing learning materials, used by 44 participants $(90 \%)$. Wikipedia was found to be a slightly less popular repository, with 34 participants $(69 \%)$, and similarly, the TED repository was reported as used by 27 participants (55\%). The Flicker repository was hardly used by participants for the purposes of learning development, and, in fact, the usage of this repository was so negligible that a statistical analysis was not computed. Only 10 participants reported that they use other repositories for learning development; 5 participants reported that they use pre-paid ShutterStock, which makes it irrelevant to the current study. Other repositories that were mentioned by individuals were Safaribooks (online professional literature), short medical videos and movies found online, internet articles, webinars, and Slideshare.

Table 2. Usage of external Little repositories

\begin{tabular}{|l|c|c|c|c|c|}
\hline & $\begin{array}{c}\text { Repository } \\
\text { Content } \\
\text { Popularity* }\end{array}$ & $\begin{array}{c}\text { Reuse } \\
\text { Uses the item } \\
\text { just as it is }\end{array}$ & $\begin{array}{c}\text { Revise } \\
\text { Creates chang- } \\
\text { es and adjust- } \\
\text { ments to item }\end{array}$ & $\begin{array}{c}\text { Remix } \\
\text { Creates changes } \\
\text { and combines } \\
\text { different learn- } \\
\text { ing items }\end{array}$ \\
\hline $\begin{array}{l}\text { YouTube } \\
\text { You Tube }\end{array}$ & $\begin{array}{c}\text { Videos and } \\
\text { Movies }\end{array}$ & $47(96 \%)$ & $51 \%$ & $\mathbf{2 6 \%}$ & $\mathbf{2 3 \%}$ \\
\hline $\begin{array}{l}\text { Google Images } \\
\text { GOOgle }\end{array}$ & Pictures & $44(90 \%)$ & $11 \%$ & $\mathbf{6 2 \%}$ & $\mathbf{2 7 \%}$ \\
\hline $\begin{array}{l}\text { Wikipedia } \\
\text { sin }\end{array}$ & Text & $34(69 \%)$ & $15 \%$ & $\mathbf{3 2 \%}$ & $\mathbf{5 3 \%}$ \\
\hline $\begin{array}{l}\text { TED } \\
\text { TED }\end{array}$ & Videos and & $27(55 \%)$ & $67 \%$ & $\mathbf{1 5 \%}$ & $\mathbf{1 8 \%}$ \\
\hline $\begin{array}{l}\text { Flicker } \\
\text { flick }\end{array}$ & Pictures & $5(11 \%)$ & - & - & - \\
\hline
\end{tabular}

* Usage Popularity column presents the number of participants using the repository and their percentage. 
The participant usage level of these repositories can be seen in the last two columns of Table 2 . Regarding Google Images, Revise and Remix were found to be $89 \%$ of all usage levels, and Reuse represented only $11 \%$. With the YouTube videos repository, Revise and Remix uses were found to be $49 \%$ of all usage types. Wikipedia also had high rates of Revise and Remix uses ( $85 \%$ of usage), and Remix was especially prominent and represented $53 \%$ of all usage. When comparing the TED video repository to YouTube, there was a similar trend. It seems that Reuse was the most popular level of use as it represented $67 \%$ of all usage, while Remix was $18 \%$ of all usage, and Revise was only $15 \%$. As mentioned previously, statistical analysis was not conducted on the Flicker repository due to the low level of participant usage; as was the case for other repositories with low levels of participant usage.

\section{Sharing of Adapted OERs}

The participants were asked to report whether they share the adapted learning resources that they retrieve from repositories and modify for their needs, and if yes, how the sharing process is carried out; 26 participants (58\%) answered positively. As for the sharing processes (Figure 5), email was the most common sharing tool (54\%). Another popular sharing process was to upload the learning resource to the organization's internal repository $(33 \%)$. Together, other types of sharing processes accounted for $13 \%$; and interestingly, a small portion of participants chose to "give back" the resource to the repository (3\%).

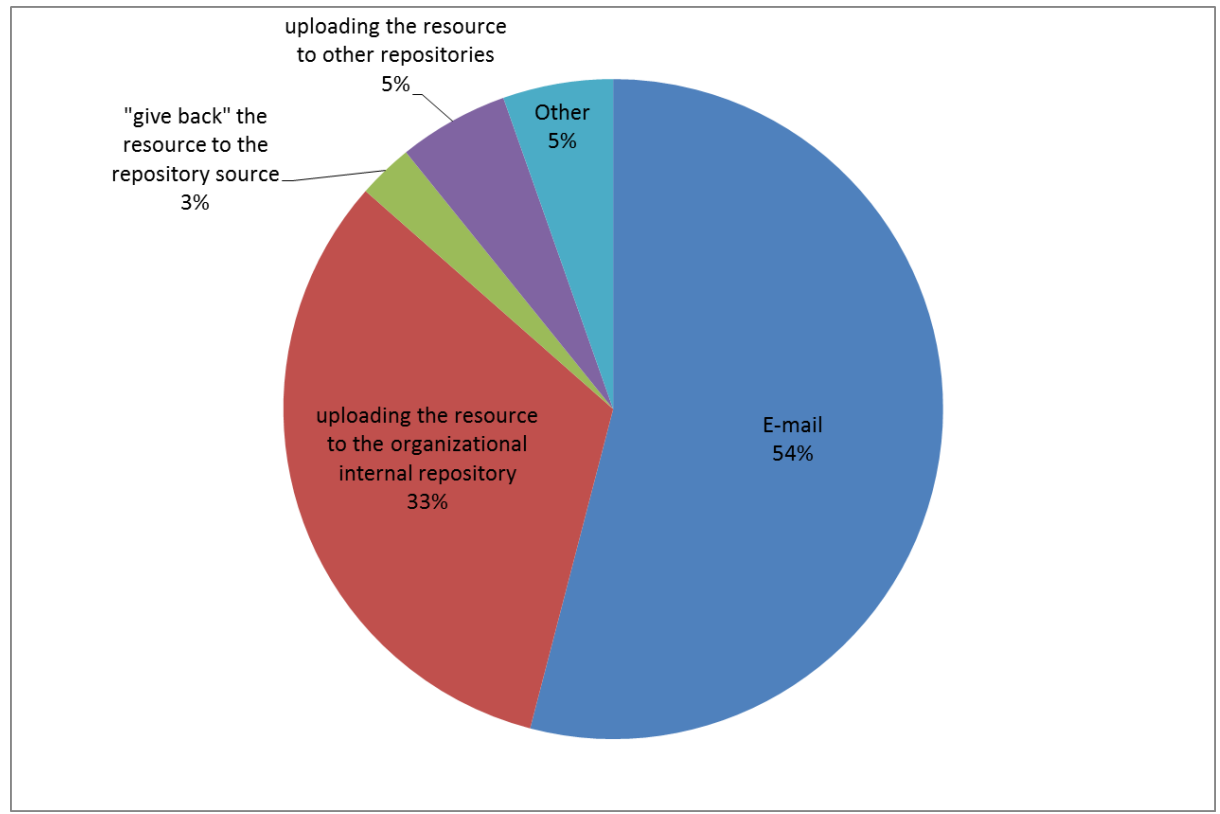

Figure 5. Sharing practices of changed learning objects

\section{The Differences between Instructional Designers and Training Managers Regarding OER Reuse Level}

In the current study, no significant differences were found between instructional designers and training managers regarding their usage levels, except for two cases. The first significant difference was found regarding the Reuse level of resources from the internal repositories and the frequency of this Reuse $[\mathrm{t}(42)=-2.375, \mathrm{p}<0.05]$. Thus, training mangers create more changes in learning resources to fit their needs than instructional designers do. The average change frequency for instructional designers $(\mathrm{M}=3.33, \mathrm{SD}=1.41)$ is lower than the average for training managers $(\mathrm{M}=4.2, \mathrm{SD}=0.9)$. The second significant difference was found regarding the Reuse level of the Google Images repository $[\mathrm{t}(47)=-1.171, \mathrm{p}<0.05]$. Instructional designers usually Reuse the 
learning items as they are, with no changes $(\mathrm{M}=2.73, \mathrm{SD}=1.09)$, while training managers tend to make changes to learning objects in order to fit them to their needs $(\mathrm{M}=3.06, \mathrm{SD}=0.69)$.

\section{Discussion and Conclusions}

\section{Characteristics of Developed OERs in Corporations}

Corporate training and learning development are mainly focused on topics such as sales, service, and technical subjects, which constitute $70 \%$ of their learning development content. This finding is not surprising, since many organizations deal with these domains, train their employees, and manage departments, which are tasks that are all targeted to these objectives. Similarly to other studies conducted in higher education (Cohen et al., 2013), the current study found that presentations and lesson plan outlines (classical learning items) were commonly used in corporate learning development. A significant gap was found between these learning items and those considered more advanced, such as educational software, tutorials, courseware, interactive videos, and simulations. This finding indicates the preferences of the instructional designers, and thus the organizations' preferences to use standard learning means rather than other learning means.

\section{The Usage of Internal Repositories}

Most of the organizations in this study have internal repositories containing learning resources, and the majority of participants use them. This finding suggests that corporations attribute importance to employee development through learning. Naturally, the operation of learning resource repositories involves an investment of numerous organizational resources, both financial and managerial. These resources might include technological infrastructure such as servers, storage, and licensed information management software. The maintenance of these infrastructures requires additional workforce employment and training, which adds to the organization's financial costs. Furthermore, resources of time and management are also required to manage these repositories, constantly checking that materials are beneficial, of good quality, indexed correctly, and updated.

Instructional designers and training managers use learning materials from internal repositories in various ways and at a similar frequency. However, a preference to Revise and Remix learning materials rather than Reuse them was identified. This finding is significantly different than the findings of former studies (Hilton et al., 2012), although it is important to emphasize that the majority of literature deals with general OER usage and did not focus on internal repositories. Still, this finding indicates the preferences of corporate instructional designers; and although internal repositories might contain items that can be useful just as they are, corporate instructional designers often choose to alter them.

\section{The Usage of Big External Repositories}

A significant portion of participants reported that they use Big external repositories. However, when asked to specify which Big external repositories they use, the majority of participants gave names of Little repositories, in spite of the fact that the questionnaire explicitly requested not to mention Little repositories when answering this particular question. Other participants mentioned repositories that were not free for use, and thus are not defined as OERs and not included in the analysis. Lacking the ability to indicate a Big OER repository may suggest that such repositories are not common among corporations. Actually, this lack might indicate characteristics of the corporations' learning development. Commercial secrets are considered to be a type of knowledge, which might contain potential competitive advantage for the organization (Liebeskind, 1996), thus it is reasonable to assume that a commercial organization will try to avoid sharing its information as much as possible. This might indicate the differences between OER initiatives as part 
of the open access movement in education, which are supporting the sharing and distribution of information, and the commercial organizations' perception, which gives preference to the use of internal repositories, without the sharing of information.

\section{The Usage of Little External Repositories}

Corporate instructional designers and training managers are using Little external repositories. The current study reveals that the majority of the examined Little repositories - YouTube, Google Images, Wikipedia, TED - are indeed used extensively for the purpose of learning development (compared to the lack of Big repositories). This finding supports the first hypothesis, that instructional designers use Little repositories, sometimes extensively.

While the literature suggests high rates of Reuse and low rates of Revise and Remix usage (Hilton et al., 2012), the current study found high rates of Revise and Remix use of pictures, videos, and Wikipedia. This finding supports the second hypothesis that Revise and Remix use is more frequent among instructional designers than the literature reports. These differences may derive from the availability of Big repositories in different fields for educators while it seems that there is a lack of such repositories for instructional designers in the corporate world. Thus, they are required to use Little repositories, which often necessitate changes and adjustment. However, these findings might also imply differences in learning material development approaches in education compared to the corporate world. It is possible that instructional designers change, adjust, and customize learning materials to fit their trainers. This assumption may be supported by the findings that show that Revise and Remix are significantly higher when using learning resources from internal repositories, as well.

Little repositories of pictures were found useful for learning development in the current study. Google Images is significantly more popular in relation to Flicker, and the usage of its resources was characterized by the Revise and Remix levels of use. Actually, in the current study, only a few participants reported Reuse of the Google Images repository, while most Revise and Remix the images (89\%). However, this can be explained by the fact that the repository contains only pictures. Naturally, a picture is not a stand-alone learning material but it may be integrated into an item such as a presentation or educational software. In addition, a picture which is integrated into a learning resource usually requires adjustment, such as resizing or changing the brightness. Adjustments can be made relatively easily with free and available editing tools, resulting in a higher level of Reuse.

Little repositories of videos were found to be useful, as well. The current study shows that YouTube is a significant repository, specifically when compared to TED. Actually, most of the participants reported using YouTube (96\%), while half of them reported using TED (55\%). A high level of Reuse was found in these video-based repositories. Half of the participants Reuse videos from YouTube and the other half (49\%) Revises and Remixes the videos. In regard to TED videos, slightly different findings were found; more than half Reuse TED videos (67\%) and only one third (33\%) of the participants Revise and Remix TED videos. Similar to the picture repository usage, video repository usage may be explained by the fact that a video usually will not stand alone, but will be part of a learning resource such as a presentation or educational software. Like a picture, a video is considered to be raw material that requires editing and adjustment to produce the final learning resource. Nevertheless, Revise and Remix usage rates are substantially lower for videos ( $89 \%$ vs. $49 \%$ and $33 \%$ ). This gap can be explained by the fact that video editing is more complex than picture editing. It requires the use of complicated editing tools that are not as standard or available as picture editing tools.

The usage level of Wikipedia (a Little repository) was found to be similar to that of Google Images: the Reuse is almost negligible (15\%) while Revise and Remix represent most of the usage 
(85\%). A specific article in Wikipedia, as a repository, does not fulfill the instructional designers' needs during the learning resource creation process. Learning resources are composed of several information pieces from several articles, meaning that the information retrieved from Wikipedia is edited, adjusted, and even combined with additional objects.

\section{Research Limitations and Future Research}

The main limitation of the current research is connected to the fact that the participants were introduced to five specific Little external repositories, and they were asked to report whether they use these repositories and at what level. These repositories were chosen due to their popularity. However, such an approach might affect the free choice of the participants, although participants were given the option to add additional repositories on their own. Another limitation is related to the targeted population, which was only partially homogenous. The study focused on two stakeholders - instructional designers and training managers - assuming they have quite similar work conditions in the development of learning materials. Differences between these two stakeholders regarding their learning material usage levels might have created a diversion in the results; although the statistical analyses reveal that the differences, if existent, have a minor effect on the results. This limitation might be a basis for further research, investigating the possibility of other differences between the two groups. Furthermore, this research focused only on Israeli organizations, and thus, in future work it will be interesting to address cultural differences. Additionally, the differences that were found between instructional designers and training managers regarding OER Reuse level were based on a rather small sample size; subsequently, further research addressing this issue should include a bigger sample size.

In future research, further and deeper exploration of the differences between corporate instructional designers, and instructional designers from the academic and educational domains will be considered, along with the attempt to understand the influence of different environments on their approaches and level of Reuse. However, it seems that the key to understanding the differences in usage levels among instructional designers lies in a better understanding of the Little repositories. In many ways, during the process of developing learning materials, corporate instructional designers have no choice but to use the Little repositories, due to (as the current study suggests) the lack of Big repositories that can fit their needs. Little repositories do not contain structured learning resources, but they do have different objects which almost always require changes, adjustments, and even combinations of several objects. Thus, it will be interesting to investigate in a complementary study whether instructional designers from educational institutions will use Little repositories at the same high level of Reuse as corporate instructional designers do. Furthermore, the finding that videos from Little OERs were reused mainly without any changes, most likely due to the difficulty of altering videos, may lead to follow up research which asks about the user's technical skills and explores whether the Reuse level has a correlation to technical skills, e.g., editing images or videos.

In summary, although the literature refers to the usage of non-institutional Little repositories for the purposes of learning, it does not describe the usage level of these repositories (Keegan \& Bell, 2011; Rolfe et al, 2012; Weller, 2010). This current study describes the usage levels of these repositories in corporations and suggests that instructional designers consider the Little repositories as significant to their work. The findings of this study give a specific glimpse into OER usage by instructional designers and training managers in corporations, and in the broadest sense, these findings contribute to the existing body of knowledge which is mostly focused on the educational and academic point of view.

The term OER can be used to describe repositories more flexibly, thereby broadening the term and making it more encompassing. Consequently, further research regarding Little repositories 
and their influence on developing learning resources is needed, whether in the corporate training world or in the higher education domain.

\section{References}

Burrus, C. S. (2014). Open Educational Resources (OER) and Connexions. Rice University, Houston, Texas, USA.

Cohen, A., Kalimi, S., \& Nachmias, R. (2013). The use of digital repositories for enhancing teacher pedagogical performance. Interdisciplinary Journal of E-Learning and Learning Objects, 9, 201-218. Retrieved from http://www.ijello.org/Volume9/IJELLOv9p201-218Cohen0861.pdf

D'Antoni, S. (2009). Open educational resources: Reviewing initiatives and issues. Open Learning, 24(1), $3-10$.

d’Oliveira, C., Carson, S., James, K., \& Lazarus, J. (2010). MIT OpenCourseWare: Unlocking knowledge, empowering minds. Science, 329 (5991), 525-526.

Duncan, S. (2009). Patterns of learning object reuse in the Connexions repository. Dissertation Abstracts International (Vol. 70, p. 73). Ann Arbor, MI: University Microfilms International.

Friesen, N. (2009). Open educational resources: New possibilities for change and sustainability. The International Review of Research in Open and Distance Learning, 10(5), 1-13.

Geith, C., Vignare, K., Bourquin, L. D., \& Thiagarajan, D. (2010). Designing corporate training in developing economies using open educational resources. Journal of Asynchronous Learning Networks, 14(3), $3-12$.

Gordon, J. \& Zemke, R. (2000). The attack on ISD. Training, 37 (4), 42-53.

Hilton, J., Gaudet, D., Clark, P., Robinson, T. J., \& Wiley, D. (2013). The adoption of open educational resources by one community college math department. The International Review of Research in Open and Distance Learning, 14(4). Retrieved from http://www.irrodl.org/index.php/irrodl/article/view/1523

Hilton, J., Robinson, T. J., Wiley, D., \& Ackerman, J. D. (2014). Cost-savings achieved in two semesters through the adoption of open educational resources. The International Review of Research in Open and Distributed Learning, 15(2)

Hilton, J., Wiley, D. A., \& Lutz, N. (2012). Examining the reuse of open textbooks. International Review of Research in Open \& Distance Learning, 13(2).

Hilton, J., Wiley, D., Stein, J., \& Johnson, A. (2010). The four 'R's of openness and ALMS analysis: frameworks for open educational resources. Open Learning, 25(1), 37-44.

Hylén, J. (2006). Open educational resources: Opportunities and challenges. Paper presented at the 2006 Open Education Conference. Retrieved from: http://www.knowledgeall.com/files/Additional_Readings-Consolidated.pdf

Johnstone, S. M. (2005). Open educational resources serve the world. Educause Quarterly, 28(3), 15.

Keegan, H., \& Bell, F. (2011). YouTube as a repository: the creative practice of students as producers of Open Educational Resources. European Journal of Open and Distance e-Learning.

Liebeskind, J. P. (1996). Knowledge, strategy, and the theory of the firm. Strategic Management Journal, 17(S2), 93-107.

Mesgari, M., Okoli, C., Mehdi, M., Nielsen, F. Å., \& Lanamäki, A. (2015). "The sum of all human knowledge": A systematic review of scholarly research on the content of Wikipedia. Journal of the Association for Information Science and Technology, 66(2), 219-245

Murphy, J., Hashim, N. H., \& O’Connor, P. (2007). Take me back: Validating the Way back Machine. Journal of Computer-Mediated Communication, 13(1), 60-75. 
Nash, S. (2005). Learning objects, learning objects repositories, and learning theory: Preliminary best practices for online courses. Interdisciplinary Journal of Knowledge and Learning Objects, 1, 217-228. Retrieved from http://www.ijello.org/Volume1/v1p217-228Nash.pdf

Orri-Badia, X., (2015). MOOCs for employees training as an upcoming elearning trend. eLearning Industry. Retrieved from http://elearningindustry.com/moocs-for-employees-training-upcoming-elearning-trend

Rolfe, V., Williams, J., \& Windle, R. (2012). HEA/JISC open educational resources case study: Pedagogical development from OER practice. Retrieved from http://www-new1.heacademy.ac.uk/assets/Documents/oer/Health_Education.doc

Roytek, M. A. (2010). Enhancing instructional design efficiency: Methodologies employed by instructional designers. British Journal of Educational Technology, 41(2), 170-180.

Shmueli, E., Reisman, S., \& Sperling, B. (2010). The new learning communities: MAOR-The Israeli learning object repository. Emerging Technologies for Online Learning.

Smith, M. S., \& Casserly, C. M. (2006). The promise of open educational resources. Change, 38(5), 8-17.

Weller, M. (2010). Big and little OER. In open Ed 2010 Proceedings, Barcelona. Retrieved from http://openaccess.uoc.edu/webapps/o2/bitstream/10609/4851/6/Weller.pdf

Wiley, D., \& Gurrell, S. (2009). A decade of development... Open Learning, 24(1), 11-21.

World Forum of UNESCO Chairs. (2002). Proposal for launching the "academics across borders" initiative. Paris. Retrieved from

http://portal.unesco.org/education/en/file_download.php/ba88fefb95a301b90e6395044552516baab do c 2002.pdf

Zervas, P., Alifragkis, C., \& Sampson, D. G. (2014). A quantitative analysis of learning object repositories as knowledge management systems. Knowledge Management \& E-Learning: An International Journal (KM\&EL), 6(2), 156-170. 


\section{Appendix}

\section{Knowledge repository usage by the training community}

\section{General}

- Age:

- Gender: Male/Female

- What is your primary role definition?

Instructional designer/training manager/other (please specify)

- Company name (optional):

- Years of experience in the training field:

- Which training topics do you deal with? (you may choose more than one) Sales/Service/Technical/Regulation/Other (please specify)

- How frequently do you develop the learning items described in the table below?

\begin{tabular}{|l|l|l|l|l|l|}
\hline & Never & Rarely & Sometimes & Often & Mostly \\
\hline Presentations & & & & & \\
\hline Lesson plan outlines & & & & & \\
\hline Educational software & & & & & \\
\hline $\begin{array}{l}\text { Educational software } \\
\text { script }\end{array}$ & & & & & \\
\hline Software simulation & & & & & \\
\hline Other 1 & & & & & \\
\hline Other 2 & & & & & \\
\hline Other 3 & & & & & \\
\hline
\end{tabular}

- If you chose Other $1 /$ Other $2 /$ Other 3 - please specify

\section{Internal repositories}

- Is there an internal repository of learning items at your workplace?

(An "internal repository" is a repository that belongs to a corporation and can only be accessed by employees. The question is referring to a repository that includes learning items such as presentations, lesson plan outlines, etc.)

Yes/No

- If yes, do you use it?

Yes/No 
- If yes, what learning items do you look for, and how frequently?

\begin{tabular}{|l|l|l|l|l|l|}
\hline & Never & Rarely & Sometimes & Often & Mostly \\
\hline Presentations & & & & & \\
\hline Lesson plan outlines & & & & & \\
\hline Educational software & & & & & \\
\hline $\begin{array}{l}\text { Educational software } \\
\text { script }\end{array}$ & & & & & \\
\hline Software simulation & & & & & \\
\hline Other 1 & & & & & \\
\hline Other 2 & & & & & \\
\hline Other 3 & & & & & \\
\hline
\end{tabular}

- If you chose Other $1 /$ Other $2 /$ Other 3 - please specify

- During training development, in which way do you use the internal repository learning items, and how frequently?

\begin{tabular}{|l|l|l|l|l|l|}
\hline & Never & Rarely & Sometimes & Often & Mostly \\
\hline $\begin{array}{l}\text { Use the learning item } \\
\text { for informational pur- } \\
\text { poses only }\end{array}$ & & & & & \\
\hline $\begin{array}{l}\text { Use the learning item in } \\
\text { its original form, just as } \\
\text { it appears in the reposi- } \\
\text { tory }\end{array}$ & & & & & \\
\hline $\begin{array}{l}\text { Make changes and ad- } \\
\text { justments to the learning } \\
\text { item according to my } \\
\text { needs }\end{array}$ & & & & & \\
\hline $\begin{array}{l}\text { Make changes and } \\
\text { combine different learn- } \\
\text { ing items according to } \\
\text { my needs }\end{array}$ & & & & & \\
\hline
\end{tabular}

\section{External repositories}

- During training development, do you use repositories existing on the internet, containing learning items?

Please note!

"Learning items" refers to items significantly targeted for learning needs, such as presentations, lesson plan outlines, etc. Please don't mention repositories where learning is not the main objective such as Google images, forums, or newsletters.

Yes/No

- If yes, please specify (up to 5 repositories)

Repository $1=$

Repository 2=

Repository 3=

Repository 4=

Repository 5= 
- In which way do you use the repository learning items you mentioned above?

\begin{tabular}{|l|l|l|l|}
\hline & $\begin{array}{l}\text { Use the item } \\
\text { just as it is }\end{array}$ & $\begin{array}{l}\text { Make changes } \\
\text { and adjustments } \\
\text { to the item }\end{array}$ & $\begin{array}{l}\text { Make changes and } \\
\text { combine different } \\
\text { learning items }\end{array}$ \\
\hline Repository 1 & & & \\
\hline Repository 2 & & & \\
\hline Repository 3 & & & \\
\hline Repository 4 & & & \\
\hline Repository 5 & & & \\
\hline
\end{tabular}

- In the table below, there are repositories of different types containing all kinds of items (which don't necessarily contain learning items). Please choose the way you use the repository items during training development.

\begin{tabular}{|l|l|l|l|l|}
\hline & $\begin{array}{l}\text { Use the learn- } \\
\text { ing item for } \\
\text { informational } \\
\text { purposes only }\end{array}$ & $\begin{array}{l}\text { Use the learn- } \\
\text { ing item in its } \\
\text { original form, } \\
\text { just as it ap- } \\
\text { pears in the } \\
\text { repository }\end{array}$ & $\begin{array}{l}\text { Make chang- } \\
\text { es and ad- } \\
\text { justments to } \\
\text { the learning } \\
\text { item accord- } \\
\text { ing to my } \\
\text { needs }\end{array}$ & $\begin{array}{l}\text { Make changes } \\
\text { and combine dif- } \\
\text { ferent learning } \\
\text { items according to } \\
\text { my needs }\end{array}$ \\
\hline YouTube & & & & \\
\hline Google Images & & & & \\
\hline Flicker & & & & \\
\hline Wikipedia & & & & \\
\hline Ted & & & & \\
\hline Other 1 & & & & \\
\hline Other 2 & & & & \\
\hline Other 3 & & & & \\
\hline
\end{tabular}

- If you chose Other $1 /$ Other $2 /$ Other 3 - please specify

- If needed, please elaborate regarding the way you use the repositories mentioned in the table above, or any other remark you may have.

\section{Sharing changes}

- In cases where you make changes to a learning item, do you share these changes? Yes/No

- If yes, how do you share the changes? (you may choose more than one)

○ By mail

- By uploading to an internal repository of the corporation

- By uploading to the repository where the item was found, which is not an internal repository 
- By uploading to a repository, which is not the repository where the item was found and not an internal repository

O Other (please specify)

\section{Remarks}

- In case you would like to add a comment or remark regarding the questions and/or the answers, please use the text box below.

\section{Biographies}

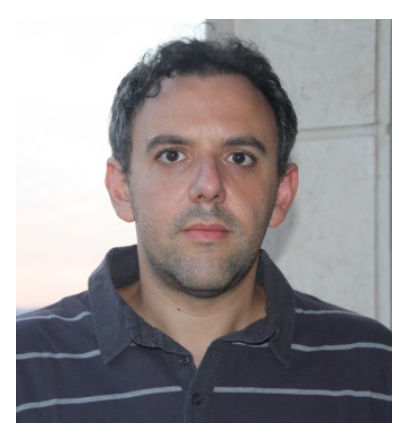

Eli Merkel is a Graduate student in Tel-Aviv University's School of Education, the Math, science, and technology education department. Eli holds a B.Sc. in Electrical Engineering. His thesis deals with benefits derived from integrating technology into the learning process in corporations, under the supervision of Dr. Anat Cohen. The thesis is based on his work as an instructional designer in a corporate.

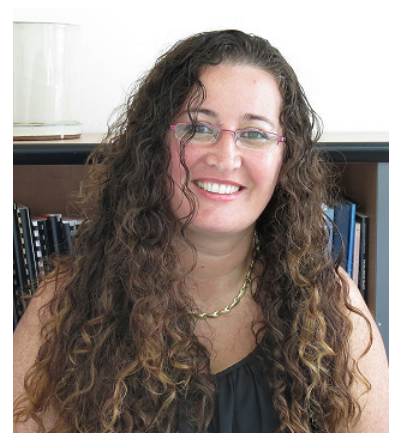

Dr. Anat Cohen $(\mathrm{PhD})$ is a senior academic staff member (on tenure track) at Tel Aviv University at School of Education; Head of the Learning and Technology program in The Department of Education in Mathematics, Science and Technology; A research and pedagogical coordinator of Web-Supported Academic Instruction at Tel-Aviv University. Dr Cohen's dissertation analysed the cost-effectiveness of Web-based Education, based on theoretical and computational models and empirical data using web-mining techniques. She has vast experience in research and teaching in the field of learning and cyber technologies after 14 years of development of online learning materials, training of academic staff, characterization of learningmanagement features fit to the University's needs, as well as research activities focusing on research areas such as social networks and privacy perception on the cyber space, internet implementation in higher education, innovative pedagogical practices using ICT, open educational resources (Learning object repositories and MOOCs), learning analytics and educational data mining. . 